\title{
Evaluating Cisco e-learning Courses Modified for the Vision Impaired
}

\author{
Helen L. Armstrong, PhD, Iain D. Murray, Member, IEEE, and Ruchi R. Permvattana
}

\begin{abstract}
The needs of vision impaired students are quite different to sighted students. The increasing use of e-learning means higher education must move to multi-modal user interfaces in order to make e-learning materials accessible to all students. E-Learning materials (particularly in the sciences and technology) are predominantly visual, presented via computer keyboard and screen. Software and devices designed to aid the vision impaired are unable to decipher most images and visualcentric objects contained in e-learning materials.

This paper discusses a project undertaken over the past two years to modify the content and presentation of Cisco certification e-learning courses to enable accessibility by vision impaired and blind students. These modifications necessitated rewriting the learning materials so they could be effectively presented via multi-modal user interfaces to vision impaired students, involving speech, audio, haptics and force-feed devices and methods.

Evaluation of sections of the project by the vision impaired students using a model based upon Stufflebeam's CIPP model and Kirkpatrick's Four-Level training program evaluation model has been carried out and the results are presented.
\end{abstract}

Index Terms - educational technology, handicapped aids, information technology, user interface human factors.

\section{INTRODUCTION}

Although the law in Australia suggests that facilities should be the same for the disabled as for able-bodied persons in reality there is still a disability divide for the vision-impaired and blind to gain equal access to education and training in many areas, particularly in IT, computer science and computer engineering.

The dominance of the sense of vision has been the focus of much research [1] [2]. Of the five body's sensory inputs, vision is the key sense used in learning. Vision also modifies or dominates the interpretation from the other senses where there is variance between the inputs from more than one sense [3]. Vision impaired and blind students do not have this facility and must rely on input from physical senses other than sight.

Manuscript received April 7, 2006.

Dr Helen Armstrong is with the School of Information Systems at Curtin University (e-mail: Helen.Armstrong@cbs.curtin.edu.au).

Mr Iain Murray is with the Dept Electrical \& Computer Engineering at Curtin University. Iain is currently working on research into multimodal HCI for the vision impaired (e-mail I.Murray@ece.curtin.edu.au).
Vision impaired students are increasingly being disadvantaged as teaching environments move to integrate more e-learning materials and methods. In computing-related disciplines in particular, there is a growing incorporation of graphics within e-learning materials to illustrate concepts being taught. Assistive technologies used by the vision impaired have difficulty translating graphical images.

This paper gives an overview of a project to modify the user interface of e-learning IT teaching software and evaluates the project's progress to date. Evaluation of the project is based upon Stufflebeam's CIPP model [4] and Kilpatrick's model for evaluating education programs [5]. The student grades obtained are presented as well as insights into their acceptance of the program and the problems they faced during their learning experience. The paper concludes with plans for the future to ensure the project remains self-sustaining.

\section{VISION IMPAIRMENT AND LEARNING}

It is important to recognize that there are different forms of vision impairment, ranging from the congenitally blind, who are blind from birth or from a very early age, through to the adventitiously blind, who lose their sight in varying degrees as a result of accidents, disease or the affects of medication. Some forms of sight impairment can be treated and improved or reversed, however congenital blindness is normally permanent. The difference between temporary and partially sighted students and permanently blind students is considerable, particularly with relation to student expectations and staff support as the two groups exhibit different study patterns and difficulties [6].

Specific conditions relating to vision impairment and their effect in a vision-centric learning environment are summarized in Table 1. Although Mann [7] developed this list for disciplines involving fieldwork, the majority of these conditions also impact learning in a computing environment.

\begin{tabular}{|l|l|}
\hline Condition & Impact \\
\hline Ocular Albinism & $\begin{array}{l}\text { Difficulties with scanning, tracking, } \\
\text { depth perception, rapidly shifting } \\
\text { visual points, reading }\end{array}$ \\
\hline Cataracts & $\begin{array}{l}\text { Wide variation in visual acuity } \\
\text { (thought full visual field usually } \\
\text { maintained) and near and far vision }\end{array}$ \\
\hline
\end{tabular}

Ms Ruchi Permvattana is a Research Associate with the Dept Electrical \& Computer Engineering at Curtin University. Ruchi is currently working on research in the design of on-line environments for the vision impaired. 


\begin{tabular}{|l|l|}
\hline & often adversely affected \\
\hline $\begin{array}{l}\text { Diabetic } \\
\text { Retinopathy }\end{array}$ & $\begin{array}{l}\text { Fluctuating visual acuity, distortion of } \\
\text { vision, and possible impairment of } \\
\text { visual field }\end{array}$ \\
\hline Glaucoma & $\begin{array}{l}\text { Progressive loss of visual field, poor } \\
\text { visual acuity, impaired peripheral and } \\
\text { night vision, and difficulty in adapting } \\
\text { between light and dark }\end{array}$ \\
\hline $\begin{array}{l}\text { Macular } \\
\text { Degeneration }\end{array}$ & $\begin{array}{l}\text { Loss or central vision (hence reliance } \\
\text { on eccentric or sideways looking), } \\
\text { difficulty in discerning fine detail and } \\
\text { reading, and problems in colour } \\
\text { discrimination (especially reds and } \\
\text { greens) }\end{array}$ \\
\hline Nystagmus & $\begin{array}{l}\text { Blurred vision, difficulty in scanning } \\
\text { and tracking, and problems with depth } \\
\text { perception }\end{array}$ \\
\hline Optic Atrophy & $\begin{array}{l}\text { Variable loss of vision and/or total } \\
\text { blindness }\end{array}$ \\
\hline $\begin{array}{l}\text { Retinitis } \\
\text { Pigmentosa }\end{array}$ & $\begin{array}{l}\text { Night blindness, narrowed field of } \\
\text { vision (resulting in tunnel vision) }\end{array}$ \\
\hline
\end{tabular}

Table 1: Impact of vision impairment conditions [7]

In general, medical conditions resulting in vision impairment are likely to affect the visual capabilities of students listed below [8]. These factors will affect the visionimpaired student's ability to physically see pictorial representations presented in learning materials on a computer screen.

- Ability to see details

- Contrast sensitivity

- Colour vision

- Accommodation to changing light levels

- Width of visual field

- Changing focus

- Seeing moving images

- Sensitivity to glare.

Of more concern in specialist fields such as information technology and engineering are the effects of the impairment on the student's ability to comprehend essential parts of the curriculum, normally taught using visual means. Education materials in IT-related disciplines traditionally rely heavily on tables and graphics to present essential concepts, methods and architectures. A diagram or picture clearly illustrates the concepts being introduced to sighted students, however, rarely are there detailed explanations of the diagram or picture in the supporting text. Blind students cannot see these diagrams and vision impaired students also have great difficulty comprehending what is being taught.

The need to play and experiment in order to learn in a computer environment is vital to the learning process. Practical application assists in the assimilation of new knowledge (supporting Piaget's theory of cognitive development) thus solidifying learning. As students with vision impairment tend to have more highly developed memory capacity than their sighted counterparts, the importance of practical experience is even more important.
Students learn by processing materials via different lanes to the brain [9]. Experimenting in a familiar and trusted environment allows vision impaired students to use multiple lanes to the brain, and thus will learn more quickly.

The second serious learning obstacle observed in students with serious vision impairment is their difficulty to comprehend spatial concepts. Jacobson, Kitchin, Garling, Gollege and Blades [10] presented the difference theory of spatial cognition, proposing that the cognitive map knowledge of adventitiously blind persons are different from sighted persons (rather than underdeveloped or used inefficiently). Individuals with no or limited vision rely on sequential learning using tactile, proprioceptive and auditory senses to construct spatial relationships and in absolute terms, limited vision leads to limited spatial knowledge [11]. Hence an alternate means of developing an understanding of more than two dimensions is required for those students with serious vision impairment.

The progress in technology has enabled teaching methods to move from predominantly textual forms to visual content and modes of delivery. Much of the learning material in IT education is also now web-based, with a predominance of images and animation. Computer-based visualisation techniques, depend almost entirely on high-resolution graphics and for vision-impaired users the problems of using complex visual displays are great.

E-learning materials are not always provided in a text-based format used by screen reading software. Many web sites are designed for purely sighted persons, with graphics, animation and multi-media interaction. Translation of many images is not possible by screen reading software. The VI student must sit through frustrating renditions detailing html tags, text colours and spacing, with no information on the image content.

There are currently only limited methods for presenting information non-visually and these do not provide an equivalent speed and ease of use to their graphical counterparts. The assistive technologies used by vision impaired and blind students may translate this information incorrectly, or not at all, leading to erroneous or different interpretations of concepts of phenomena. While computerbased learning has opened opportunities for many students with disabilities, it remains primarily vision dependent.

In order to make IT training and education materials more accessible by vision impaired and blind students, the authors are currently undertaking a project at Curtin University to convert Cisco e-learning modules into formats accessible by assistive technologies used by the disabled students.

\section{CISCO TRAINING FOR THE VISION IMPAIRED}

In conjunction with the Association for the Blind WA and Cisco Systems, the School of Electrical \& Computing Engineering have embarked upon a program to investigate the needs of vision impaired students subjected to on-line education courses in computing, and develop alternate means of accessing and presenting the teaching and learning 
materials. The School of Electrical and Computer Engineering is a recognized Cisco Learning Academy, and has taught Cisco courses to sighted students since 2000.

Over the past two years academic staff members have been converting Cisco e-learning courses and teaching these courses to vision impaired and blind students at Curtin University. This project provides the vision impaired students with industry-level certification to aid employment as well as an avenue for enrolment in higher education courses. The main focus of the project is the conversion of the Cisco elearning modules into formats more accessible by students with vision disabilities.

The Cisco courses included in the project to date are Information Technology Essentials I and II (ITE1 and ITE2) and Cisco Certified Network Associate I and II (CCNA1 and CCNA2). These courses form part of the Cisco CNAP (Cisco Networking Academy Program). The CNAP courses are widely accepted as industry standard certification courses on information technology and computer networks.

Unfortunately, the Cisco curriculum is traditionally delivered as Flash web pages. This style of delivery is unsuitable for vision impaired persons. The arrangement of frames is unsuitable for screen review applications (speech output), but more importantly the curriculum relies heavily on visual keys to illustrate learning objectives.

Several problems, not apparent to most sighted users, are also inherent in the curriculum design. The first problem is that the diagrams are extremely difficult to access or even explain to a person who has been blind since birth. The second problem is that the arrangement of frames and the lack of correct ALT labels (text equivalent buttons) add to the complexity of the presented material. The vision impaired students also advise they have no way of accessing the content of interactive sessions and find the supporting text confusing and misleading.

The conversion process has involved the following tasks -

- transcription of the materials into Braille

- rewriting sections presented in tables to illustrate the raw data (router rules, etc.)

- rewriting sections referring to figures, diagrams, and photographs, to provide a full-text explanation of the content of the images

- textual description of animation used in images

- tactile printing of diagrams (raised print on the paper)

- development of other manual assistive tools such as peg boards for hex conversions, network domino tokens with Velcro backing for developing network architectures

- function generator attached to a vibrating speaker for frequency and amplitude

- $\quad$ tactile circuit board with enlarged ports and plugs.

Further details of the teaching aids used in the project can be found in Murray and Armstrong [12].

\section{THE VISION IMPAIRED STUDENTS}

A total of 19 vision impaired students have participated in the Cisco program so far. All participating students are legally blind (having $<10 \%$ vision or a field loss down to 10 degrees). Some of the vision impaired students have medical conditions such as retinitis pigmentosa which results in tunnel vision. Others have conditions such as optic atrophy or diabetic retinopathy which can result in distortion or impairment of the visual field and total blindness. Others have blindness caused by cancer, glaucoma, inter-cranial hypertension and other medical conditions resulting in a variety of impairments. Accidents have also resulted in blindness for some of the students. One of the first tasks in the learning environment under research is to determine each student's sight impairment, and the underlying medical condition, as this will be a guide in determining the most appropriate assistive technologies for that student.

The students range in age from 18 to 55 and have a variety of technical ability and prior experience. Ten of the group have no useful vision and rely on Braille and screen reading software, and the remainder access a computer with screen enhancement software. One student is deaf and blind requiring screen enhancement and Auslan sign language.

The vision impaired students use the same materials, assessments, laboratories, equipment and teaching staff as the sighted students. The only differences in the classes between the sighted and vision impaired students are

- The e-learning modules have been converted into formats accessible by the blind students.

- The vision impaired students attend separately scheduled laboratory classes due to the high levels of noise generated by sighted groups. This noise competes with the speech output modules used by the vision impaired students.

- The vision impaired students need approximately twice as much time to complete the modules due to the time required for speech output.

By taking a 'snapshot' of each student at their starting point, we are able to determine the extent of their disability, their knowledge of Braille, their familiarity with assistive technologies, and their knowledge of IT and computer networks. Details of their vision ability and disability are provided by the Association for the Blind and appropriate assistive technologies are established on workstations for each student. Students sit a Cisco test to determine their knowledge level of IT and networks at the commencement of the course. This allows the teacher to see any gaps in their knowledge as well as the level of their knowledge in pertinent areas.

The vision impaired students use the converted learning materials on workstations fitted with the appropriate assistive technologies. In addition to two main sighted instructors, two vision impaired instructors also assist with the teaching. The vision impaired instructors have completed the Cisco modules previously and have also sat and passed the Cisco Instructors examination for the modules being taught. The vision 
impaired instructors are able to explain concepts to the students using familiar terminologies and concepts.

\section{THE EVALUATION PROCESS}

In traditional scientific experiments it is common to compare the results of an experimental group with a control group. In this particular project this would entail dividing the vision impaired students into two groups. One group would be given the usual e-learning materials and the other would use the converted materials. Unfortunately the inaccessibility of the e-learning materials means the control group of vision impaired students would be able to access only a small portion of the materials, and much of it would be disjointed and out of context. We have therefore decided to evaluate the success of the program using other methods.

Two recognized models for evaluating training programs formed the basis of the evaluation approach used for this project. Stufflebeam's CIPP (context, inputs, process, product) model [4] and the Kirkpatrick Four Levels evaluation model [5]. Both models have been widely used in evaluating training and education programs. Although the two base models chosen have been later enhanced to incorporate further consideration of economic viability and other factors, these were not viewed as pertinent to the project under study.

The original CIPP model is briefly described as -

- Context - considers the needs to be addressed and assists in establishing the program's objectives.

- Input - considers alternative strategies and the use of resources in order to meet the stated objectives.

- Process - considers monitoring the implementation, assessing progress, and identifying barriers to success.

- Product - considers outcomes of the program, attainment levels and feedback for the next cycle.

In Stufflebeam's words [13] the four parts of the evaluation process respectively ask, "What needs to be done? How should it be done? Is it being done? Did it succeed?"

Kirkpatrick's four-level model measures [5]-

- Reaction -what delegates thought and felt about the learning experience

- Learning - the resulting increase in knowledge or capability

- Behaviour - extent of capability improvement and application

- Results - effects on the business or environment resulting from the trainee's performance.

The evaluation process used in this project combined these two approaches to develop the model illustrated in fig. 1 . The new model features consideration of

- the Context of the study - identifying the needs of the target group and defining objectives of the program based upon those needs,

- the Process undertaken - including the content incorporated, the methods and approaches used in the conversion and presentation of the materials and the assessment of students,
- the Resources used - including people, skills, equipment, materials, time, money, etc.,

- the end Product - incorporating measurement of the change in ability, knowledge levels, capability to apply the knowledge gained, and effect on the student's environment related to the need or objective,

- input from the stakeholders involved - including the students, the teachers, the funding body, employers, etc.

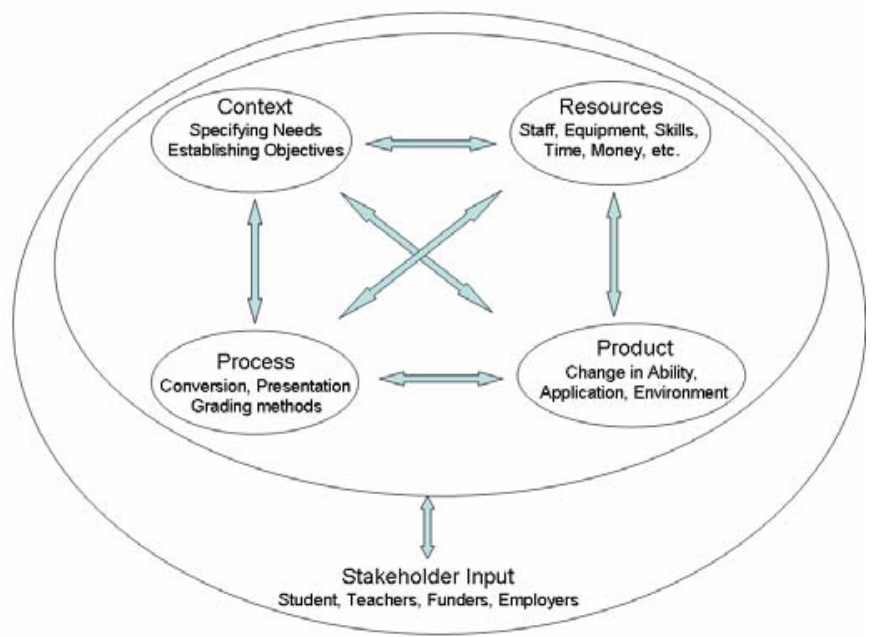

Fig. 1. Combining Stufflebeam's CIPP model [4] and Kirkpatrick’s Four Levels model [5].

In order to be effective there needs to be constant two-way flows between all the components. The arrows in figure 1 signify the ongoing monitoring and feedback mechanisms to aid this process. As the focus of the project thus far concentrates on improving the accessibility of the e-learning materials for the vision impaired students, evaluation was sought from only these students. Input from other stakeholders will be gathered at later stages of the research.

Based upon the above model, it was decided to gather feedback from the vision impaired students on a number of areas relating to the evaluation model components. The profile of each student's vision impairment was considered and their use of assistive technologies to determine individual needs in the light of the learning objectives set, to aid in consideration of the Context factors. The students were requested to rate the converted course materials and teaching methods to assist in assessing the Process factors. To cover the Resources, the students were requested to rate equipment and assistive technologies used and the teaching staff involved. To evaluate the Product we requested the students provide their perceptions of their level of skills and knowledge, and employability, before commencing the course and now.

\section{Evaluation By the StUdents}

Although it was expected that the sight impaired students would achieve lower grades than the sighted students, this has not been the case. Prior to the commencement of the Cisco 
modules sighted students generally achieve slightly higher grades than the vision impaired students. The researchers have found that once the vision impaired students undertake the modified Cisco curriculum there is no discernable difference in the marks between the two groups. The average marks gained by the sight impaired students in the intakes so far (utilizing the modified teaching materials) do not differ significantly from those achieved by the sighted students using the traditional Cisco materials.

The Cisco examinations have a pass mark of $75 \%$. There was no discernable difference in the average scores of the sighted and vision impaired groups in the 2004 intake, with both groups achieving an average of $92 \%$ in the Cisco examinations for the Cisco courses. The 2005 intake of vision impaired students gained an average of $86.82 \%$, compared to 83.99\% for the sighted student group in the same assessments.

These results give us confidence that the vision impaired students are able to gain access to the required learning materials and methods at a level that is equitable to those accessible by the sighted students. It also confirms that the conversion of the materials into formats accessible and comprehendible by the sight impaired students is, at worst, adequate, however more research into this area is needed.

The vision impaired students have been interviewed on a number of occasions over the past three years and also completed questionnaires to assist with the evaluation. The questionnaire designed for this evaluation process collected data on a number of areas for evaluation, including the quality of the converted Cisco teaching materials, the equipment and assistive technologies used in the labs, the sighted instructors, the vision impaired instructors, their knowledge of IT and computer networks before and now, how much they use the skills and knowledge they have gained, their employability before and now, improving their effectiveness on the job, problems encountered while doing the training, whether they prefer to work alone or in a group, and Curtin University as a venue for the training. A Likert scale of 1-5 (where 1 is low and 5 high) was used to rate factors under study.

Eleven students submitted completed questionnaires, five of these students are totally blind, relying on Braille and screen reading software, and the remaining six have very low vision, relying on screen reading software and screen enlargement. A summary of the data collected can be seen in table 1 .

The converted Cisco courses gained an average rating by the vision impaired students of 3.56. Ratings of the quality of the learning materials appears to have increased over the period of the research. Students enrolled in the courses early in the project generally rated the converted materials lower than students undertaking them during the past twelve months. This could be due to minor enhancements being made to the materials on an ongoing basis. The use of vision impaired instructors who had previously undertaken and completed the same learning experience could also have affected the ratings.

The majority of the students rated the equipment highly, achieving an average rating of 4.33 out of 5 . Comments included "equipment has been of the highest standard.", "computers have been upgraded”, "a good consistent quality”, "has always been of a high standard and always Cisco corporate networking equipment, what more could you ask for”.

TABLE 1: RATINGS BY THE VISION IMPAIRED STUDENTS

\begin{tabular}{|l|c|c|c|}
\hline $\begin{array}{l}\text { Factor to Rate } \\
\text { (1=low, 5=high) }\end{array}$ & Lowest & $\begin{array}{c}\text { Highes } \\
\text { t }\end{array}$ & Average \\
\hline $\begin{array}{l}\text { Converted Cisco } \\
\text { materials }\end{array}$ & 2.00 & 5.00 & 3.56 \\
\hline $\begin{array}{l}\text { Equipment and } \\
\text { Assistive Technologies }\end{array}$ & 3.00 & 5.00 & 4.33 \\
\hline Sighted Instructors & 4.00 & 5.00 & 4.89 \\
\hline $\begin{array}{l}\text { Vision Impaired } \\
\text { Instructors }\end{array}$ & 1.00 & 5.00 & 3.75 \\
\hline IT knowledge Before & 1.00 & 3.00 & 1.35 \\
\hline IT knowledge Now & 3.00 & 4.50 & 3.90 \\
\hline Use of skills obtained & 3.00 & 4.50 & 4.00 \\
\hline Employability Before & 1.00 & 2.00 & 1.11 \\
\hline Employability Now & 3.00 & 5.00 & 3.78 \\
\hline $\begin{array}{l}\text { Improved effectiveness } \\
\text { on the job }\end{array}$ & 3.00 & 5.00 & 4.35 \\
\hline
\end{tabular}

The sighted instructors were rated very highly with an average rating of 4.89 out of 5 . Comments included "Understanding and willing to assist where necessary, forward thinking”, "excellent”, "quite good regarding knowledge, but sometimes too busy", "very helpful with VI issues and also questions and errors in course content", "keen to learn what we needed, listened to our ideas and tried them out, as well as trying out his own ideas", and "thorough and comprehensive". The vision impaired instructors rated slightly lower than the sighted instructors, with an average rating of 3.75 out of 5 .

The majority of students rated their knowledge before commencing the training at level 1 - very low, with the exception of one student who had some prior knowledge. The average knowledge level at commencement was 1.35 out of 5 compared to an average of 3.9 now. All students noted an increase in their knowledge levels, with the group averaging an increase of 2.55 levels. Similar ratings were given for the employability of the students, with an average of 1.11 before the training and 3.78 now. The application of the skills and knowledge was rated quite highly by the students with an average of rating of 4.0 out of 5 . The students also considered their effectiveness on the job was now high, with an average rating of 4.35 .

\section{DIFFERENCES IN LOW VISION AND BLIND RESPONSES}

Although the ratings from the entire group were positive, there appears to be distinct groupings of students based upon their ratings and answers to the questions. The groupings coincided with the amount of vision, with the totally blind students forming a distinct subgroup within the participants.

Generally, the totally blind students had more problems with the Cisco training, particularly with images, tables, Flash 
pictures, network diagrams, animated graphics, interactive sessions and photographs. They were less sure of their ability to successfully complete the programs, and faced more learning and understanding problems during the training. The totally blind students were also the most optimistic with regard to an increase in their employability, the application of skills and knowledge they had gained from the training, and their effectiveness on the job.

The totally blind students were less accepting of the university as an ideal location, mainly due to the continuous stream of building projects on campus and the changing of roadways and pathways. The low vision students liked studying on the campus, sharing the same facilities as sighted university students, and being included in campus activities.

As expected the totally blind students were more reliant on Braille and screen reading software than the vision impaired students. Due to the high percentage of totally blind students in the classes, the course notes are being converted into Braille, and Braille Display equipment is used in the network laboratory to transcribe screen output into Braille. Braille labels are also used on equipment and tactile print-outs.

In addition, the totally blind students predominantly preferred to work alone, rather in groups. Perhaps this is a reflection of their past experiences, where most activities have been undertaken alone. The low vision students predominantly preferred to work in a group.

With regard to the teaching materials, the students rated the Cisco modules that had been completely converted much higher in acceptance and accessibility than the newer modules which were still undergoing conversion. The totally blind students rated the converted programs lower than the vision impaired students (average blind $=2$ out of 5, vision impaired average $=4$ out of 5). Rating of the vision impaired instructors indicated the vision impaired students were more accepting than the totally blind students (blind average $=3$ out of 5 , vision impaired average $=4.2$ out of 5 ). The totally blind students claimed the vision impaired instructors were not always understanding and attentive to their needs.

\section{WHERE TO FROM HERE?}

The responses from the students for the converted Cisco modules has been encouraging. Upon completion of the courses currently under conversion a further evaluation on the same criteria will be conducted by the students. In addition, feedback from other stakeholders will be sought in order to build a bigger picture of the project results.

The project has been presented a Cisco award and conferred the first Cisco Academy for the Blind. It is planned to move the project from Curtin University to the Association for the Blind Western Australia within the next twelve months. The Association will then take on the responsibility for the ongoing management of the Cisco Academy for the Blind. Further vision impaired instructors are currently in training and plan to be qualified to teach the courses by the time of the move. This project is a small contribution to equal opportunity for the vision impaired.

\section{REFERENCES}

[1] T. Thesen, J.F. Vibell, G.A. Calvert \& R.A. Osterbauer, "Neuroimaging of multisensory processing in vision, audition, touch, and olfaction”, Cognitive Processing, June 2004, Vol. 5, No. 2, pp 84-93

[2] C. Spence, B. Kettenmann, G. Kobal \& F.P. McGlone, "Shared attentional resources for processing visual and chemosensory information”, Journal of Experimental Psychology, August 2001, Vol. 54, No. 3, pp 775-783

[3] D.I. Shore \& R.M. Klein, "On the manifestations of memory in visual search”, Spatial vision, January 2001, Vol. 14, No. 1, pp 59-75

[4] D.L. Stufflebeam, (1985). Stufflebeam's improvementoriented evaluation. In D. L. Stufflebeam \& A. J. Shinkfield (Eds.), Systematic evaluation (Chapter 6, pp. 151-207). Boston: Kluwer-Nijhoff.

[5] D.L. Kirkpatrick, “Evaluating Training Programs”, 1975, American Society for Training and Development (ASTD), USA.

[6] I. Shepherd, "Providing Learning Support for Blind and Visually Impaired Students Undertaking Fieldwork and Related Activities”, University of Gloucestershire, 2001, Available: http://www.glos.ac.uk/gdn/disabil/.

[7] Mann, K. "Disabilities and their characteristics”, 1999, Available: http://www.wmin.ac.uk/ccpd/uow/dict.htm.

[8] SCC (Scottish Sensory Centre), "Visual Impairments", 2000, Available: http://www.ssc.mhie.ac.uk/VI_Video/N_VIDEO/VINEEDS /VITYPES/VITypLnk.htm.

[9] Sprenger, M. "Learning and Memory: the Brain in Action”, 1999, ASCD, VA, USA.

[10] Jacobson, D., Kitchin, R., Garling, T., Golledge, R. and Blades, M. "Learning a Complex Urban Route Without Sight: Comparing Naturalistic versus Laboratory Measures”, Proc. Mind III: Annual Conference of the Cognitive Science Society of Ireland, 1998, University College, Dublin.

[11] Bigelow, A.E. "Blind and Sighted Children's Spatial Knowledge of the Home Environments", 1996, International Journal of Behavioural Development, 19: 797808.

[12] I.D. Murray \& H.L. Armstrong, "Teaching Sight Impaired IT Students”, Proceedings of Educause 2005, Auckland, April 5-8, Paper B5, Available: http://www.educause.auckland.ac.nz/interactive/index.cfm? action=papers

[13] D. L. Stufflebeam, “CIPP Evaluation Model Checklist”, 2002, Available: http://www.wmich.edu/evalctr/checklists/cippchecklist.htm 